\title{
Detection Sensitivity of Iron-Foil Corrosion Sensor in Simulated Concrete Solution
}

\author{
Akira Eriguchi $^{1}$, Hiromi Fujiwara ${ }^{2}$, Hayato Itaya $^{3}$, Toru Wakabayashi ${ }^{3}$, \\ Shunsuke Otani ${ }^{3}$ and Yukitoshi Isaka ${ }^{1}$ \\ ${ }^{1}$ Taiheiyo Cement Corporation Central Research Laboratory, Osaku, Sakura, Chiba, Japan, \\ akira_eriguchi@taiheiyo-cement.co.jp \\ ${ }^{2}$ Utsunomiya University, Yoto, Utsunomiya, Tochigi, Japan, fhiromi@cc.utsunomiya-u.ac.jp \\ ${ }^{3}$ Nakabohtec Corroosion Protecting Corporation, Innovation and Technology Center, Nakaarai, Ageo, \\ Saitama, Japan, h.itaya@nakabohtec.co.jp
}

\begin{abstract}
This examined the performance of the iron-foil sensor in concrete and its relationship with the amount of chloride in the solution simulating concrete. The corrosion sensor reacted at a chloride ion concentration of $500 \mathrm{ppm}$. From the results, it was inferred that the sensor has a high sensitivity. Furthermore, to evaluate the performance of the sensor, it was built a wireless system using radio-frequency identification (RFID), embed it into an actual concrete structure, and subsequently initiate observation.
\end{abstract}

Keywords: Corrosion, Sensor, Chloride Ion, Monitoring, Solution Simulating Concrete.

\section{Introduction}

Corrosion of the internal steel in reinforced concrete structures is a degradation phenomenon that causes cracks and significantly reduces structural strength. The ASTM C876-15 (2015) standard self-potential method and polarization resistance method of the CEB Working Group (1997) are widely used methods of confirming the soundness of the internal reinforcing steel. However, since those methods require running cable to the reinforcing steel, in practice they can require breaking parts of the structure. Even if the cables are installed in advance, it is difficult to ensure their long-term durability. Moreover, those methods represent a post hoc diagnostic approach that checks for corrosion for purposes of corrective maintenance. Once corrosion is confirmed, deterioration has likely already advanced.

For this reason, Lee and Shin (2003) and Takewaka and Yamamoto (2001) have been developing and studying sensors for monitoring corrosion in steel. In order to enable preventive maintenance by predicting the possibility of corrosion in advance, many of these sensors electrically identify corrosion, not in the reinforcing steel itself but in steel materials that act as a proxy for the reinforcing steel. Therefore, the sensors are able to identify corrosion with no damage to the structure. Furthermore, by identifying the risk of corrosion of the reinforcing steel at an early stage, the sensors enable a more efficient consideration of follow-up countermeasures.

We have developed a corrosion environment sensor that consists of a reinforced iron-foil. If the corrosion factors reach the sensor, the sensor itself will corrode and rupture. The sensor 
is designed to detect the occurrence of corrosion by sensing the change in electrical resistance when the rupture occurs. To evaluate the performance of the corrosion environment sensor, we varied the concentration of chloride ions in a simulated concrete test solution and determined the point at which the sensor ruptured, thereby verifying the sensitivity of the corrosion environment sensor to the chloride concentration.

In order to develop the corrosion environment sensor into a practical system, we additionally designed a completely non-destructive monitoring system using passive radio-frequency identification (RFID), a close-proximity wireless technology, and installed it in an actual structure for use as a measurement and monitoring system.

\section{Structure and Mechanism of the Corrosion Environment Sensor}

The sensor consists of a circuit formed on an iron-foil positioned on top of a resin film as shown in Figure 1. The iron-foil is $0.01 \mathrm{~mm}$ thick and made of pure iron. The circuit is similar to a simple single conducting wire. When measured, the value of the electrical resistance between both ends is $15 \Omega$ or less. However, if the sensor itself becomes corroded enough to disconnect, it will show a resistance of $100 \Omega$ or more. Precious metals are deposited on the surface at the ends of the iron-foil to serve as cathode electrodes, making the film highly sensitive to corrosion. As shown in Figure 2, the iron-foil sensor is integrated into a ceramic housing and the surface is covered by mortar. This structure is designed to maintain an alkaline environment that prevents corrosion due to atmospheric factors, such as humidity.
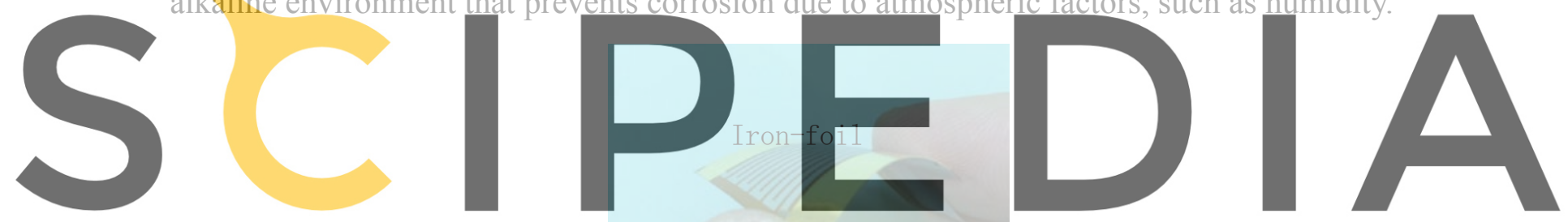

\section{Register for free at https//www.scipedia.com to download the version without the watermark}

\section{Figure 1. Appearance of the corrosion sensor}

\section{Performance Testing of the Sensor}

Since the sensor is made of iron, which is the main component of the reinforcing steel inside the concrete, it also suffers corrosion as corrosion factors from the environment penetrate into the concrete, increasing the risk of corrosion of the reinforcing steel. The sensor simply evaluates whether or not the iron has corroded, but cannot determine the cause of corrosion.

Although corrosion degradation of reinforcing steel is thought to occur due to multiple factors, the main factors include the rupture of the passive film due to salinity, reduction of alkali anti-corrosion protection due to carbonation, and penetration of moisture and oxygen. In Japan, the specifications of the Japan Society of Civil Engineers warn that steel corrosion occurs when the concentration of chloride ions in the concrete reaches $1.2 \mathrm{~kg} / \mathrm{m}^{3}$ or higher. There are also regulations in each country on the permissible chloride concentrations in the materials that make up concrete. In Japan, the concentration is generally capped at $0.30 \mathrm{~kg} / \mathrm{m}^{3}$. 


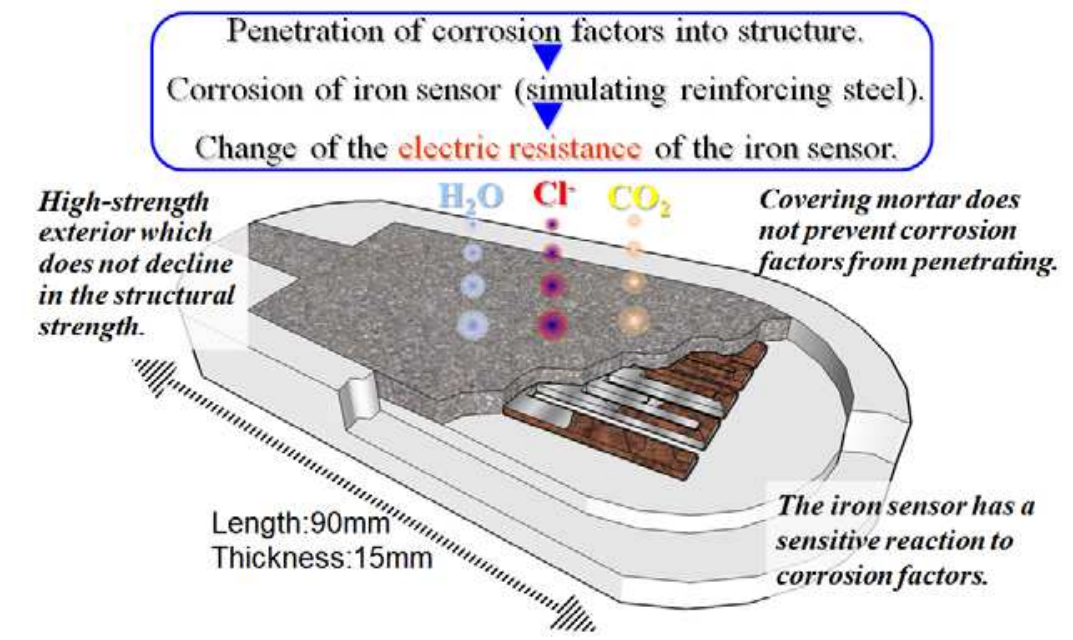

Figure 2. Overview of the corrosion sensor and its working.

From this perspective, we can evaluate the performance of the sensor by quantitatively capturing the penetration of chloride ions, which can cause degradation, and determining the relationship between the concentration of chloride ions and the detection performance of the sensor.

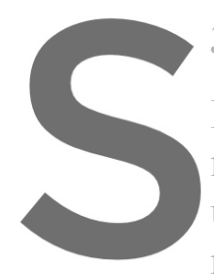

\subsection{Overview of Perfor}

Performance testing

mimic the internal envirc

uniform $\mathrm{pH}$ and chlorid

needed during testing to
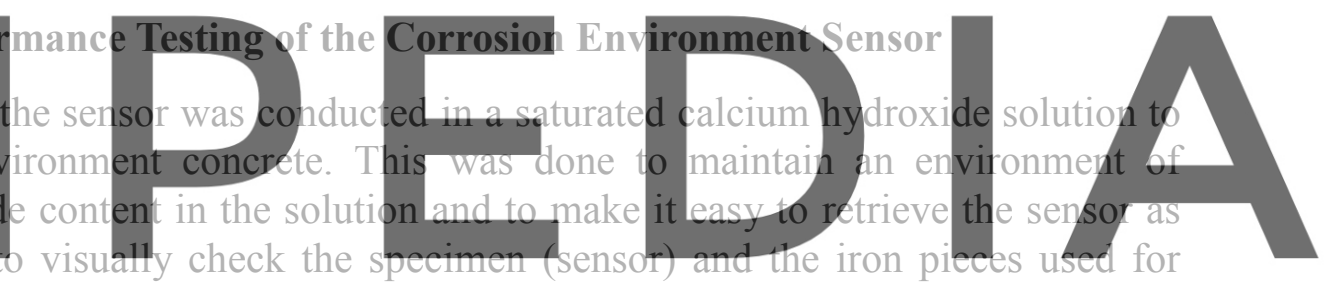

comparison.

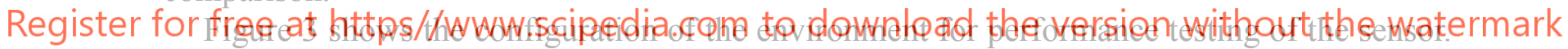

An air pump was used to vent air into the saturated aqueous solution of calcium hydroxide.

The carbon dioxide in the air reacted with the calcium hydroxide test solution, preventing the lowering of its $\mathrm{pH}$, as indicated in Table 1. After the carbon dioxide was removed, the air was fed into the test tank. We periodically measured the $\mathrm{pH}$ of the test solution to ensure that its $\mathrm{pH}$ did not change.

If the sensor reached a resistance value of $100 \Omega$ or more after the start of the test, it was considered ruptured. We tested five sensors per test level.

\subsection{Verification of Corrosion Rate Using Steel}

In order to understand the corrosion rate of each chloride ion concentration in the simulated concrete test solution, we immersed a sample of SS400 steel, of dimensions $20 \times 80 \times 2 \mathrm{~mm}$, in the solution using the same test equipment configuration used to test the corrosion environment sensor.

To obtain the corrosion rate of the steel, we immersed a steel sample in each of the aqueous solutions shown in Table 1 and measured the reduction in the mass of the steel before and after the test. We tested five steel sheets per test level. 


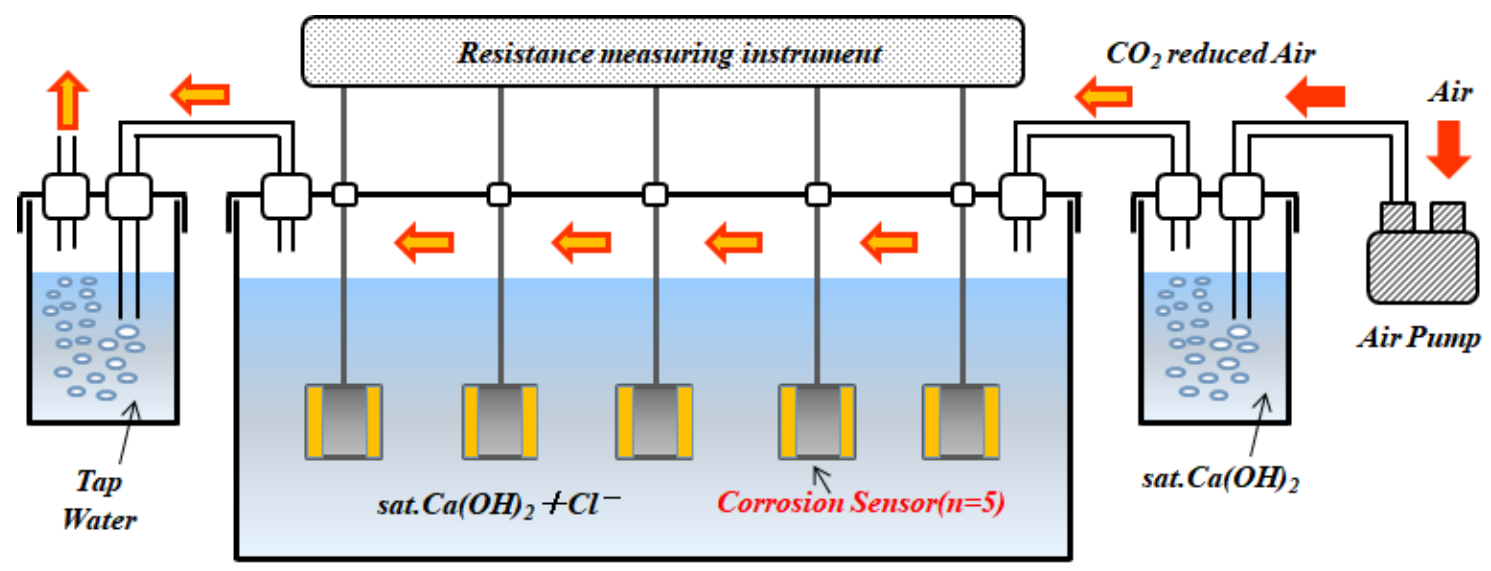

Figure 3. Configuration of the corrosion sensor evaluation experiment.

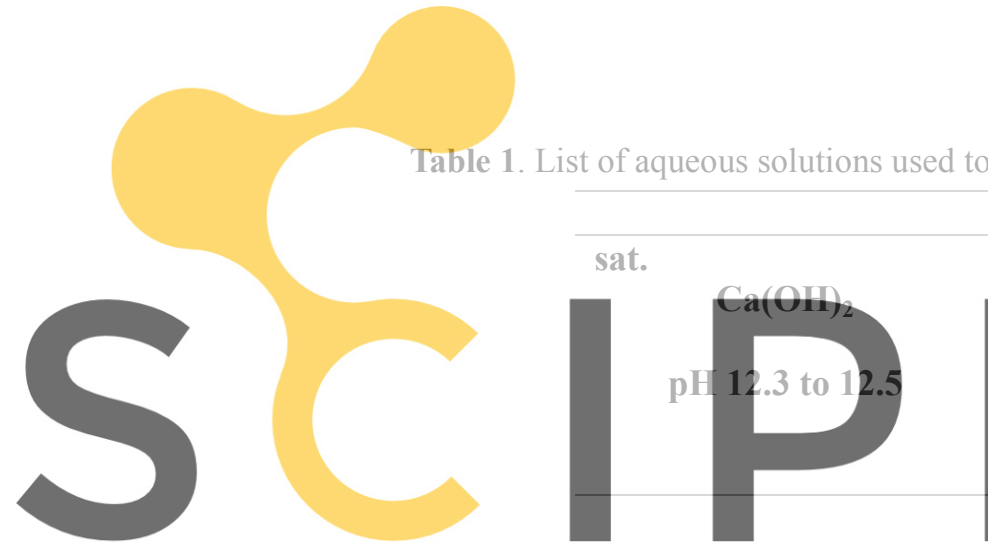

To obtain the reduction in the mass of the steel after rust removal, we immersed the steel in

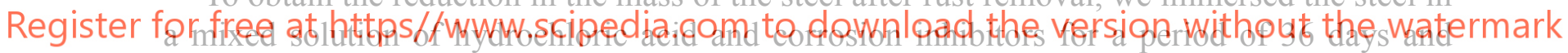
then measured its mass. We subtracted this value from the mass of the steel measured before the test to obtain the reduction in mass.

\section{Results of Performance Testing}

\subsection{Detection Performance of the Corrosion Environment Sensor}

Figure 4 shows the time taken for each sensor to rupture. The earliest rupture occurred at the chloride ion concentration of $5000 \mathrm{ppm}$. At the chloride ion concentration of $200 \mathrm{ppm}$, no rupture was observed, even after 2500 hours. The graph shows that the sensor rupture time tends to increase as the concentration of chloride ions decreases. In particular, the chloride ion concentration of $500 \mathrm{ppm}$ produced the longest rupture time, which was 1700 hours (about 70 days). The chloride ion concentrations of $500 \mathrm{ppm}$ and $5000 \mathrm{ppm}$ showed a difference in average rupture time of about 1000 hours.

Figure 5 shows the result of converting the horizontal axis of Figure 4 to represent the relative concentration between $\mathrm{Cl}^{-}$and $\mathrm{OH}^{-}$at a $\mathrm{pH}$ of 12.1 . The sensors ruptured when $\mathrm{Cl}^{-} / \mathrm{OH}^{-}$was 0.71 or greater. There are various theories about steel corrosion thresholds based 
on $\mathrm{Cl}^{-} / \mathrm{OH}^{-}$, but given that our test results are within the range of 0.6 to 1.0 reported of $\mathrm{D}$. A. Hausmann (1967) in related literature, we can conclude that the sensor is able to rust and rupture with reasonable sensitivity.
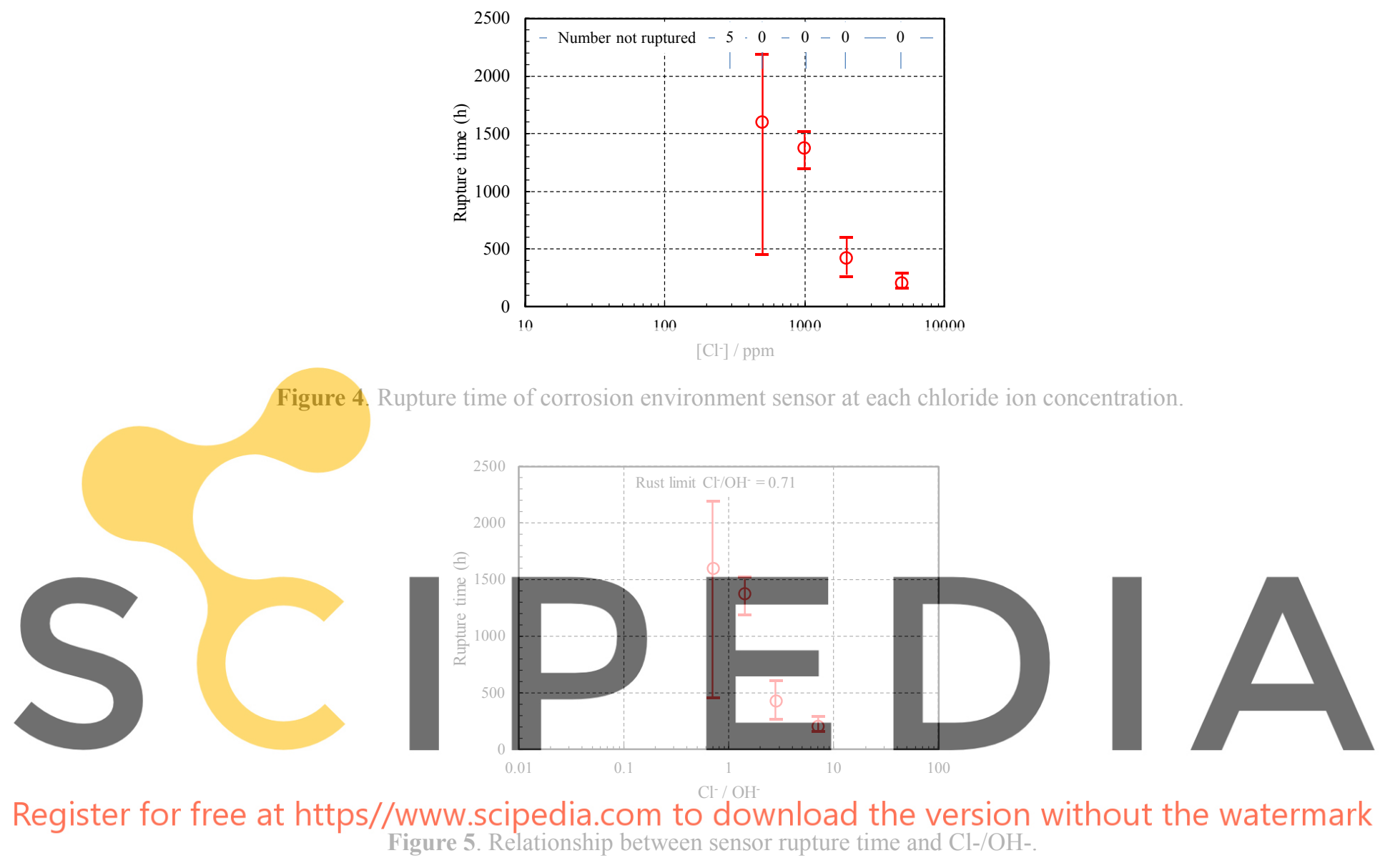

\subsection{Results of Steel Corrosion Rate Test}

Figure 6 shows the corrosion rate of steel in the different aqueous solutions. In this test, the steel in the test solution with a chloride ion concentration of $200 \mathrm{ppm}$ showed a corrosion rate of $0 \mathrm{~mm} / \mathrm{y}$, i.e. no corrosion. As the concentration increases from $500 \mathrm{ppm}$, the corrosion rate also increases. These results are similar to the differences in the rupture time of the sensors shown in Figure 4. At the chloride ion concentration of $500 \mathrm{ppm}$, a very small corrosion rate of $0.0001 \mathrm{~mm} / \mathrm{y}$ was observed. Since the corrosion rate of steel in seawater is $0.1 \mathrm{~mm} / \mathrm{y}$, the fact that the sensor ruptures under conditions at which the corrosion rate of steel is approximately $0.001 \mathrm{~mm} / \mathrm{y}$ suggests that the sensor has a highly sensitive reaction to the chloride ion concentration.

In alkaline environments, steel tends to form a passive film due to the supply of oxygen. In our testing environment, the air pump is used to inject oxygen partial pressure into the simulated concrete test solution under conditions that are close to natural. In evaluating the corrosion rate, it is important to prevent excessive increases in the oxygen partial pressure. 


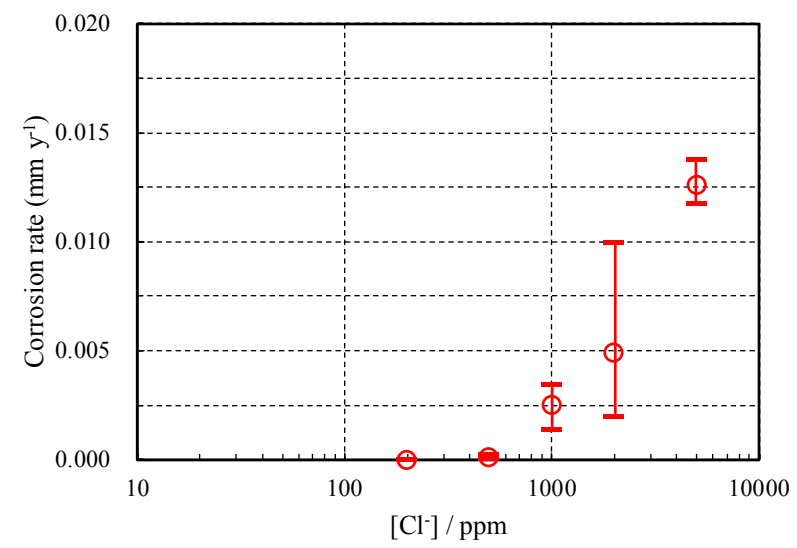

Figure 6. Corrosion rate of steel at each chloride ion concentration.

\section{Measurement System of the Sensor}

As explained above, the sensor detects whether the environment has become corrosive by measuring the electrical resistance in the sensor itself. This makes it easy to identify a corrosive environment by embedding the sensor in the structure and measuring the electrical resistance with a simple tester through a cable. However, to evaluate the corrosion environment inside a

outside environment fo

connectors or deterioration

We therefore investi

wireless measurement st

money transfers. This s
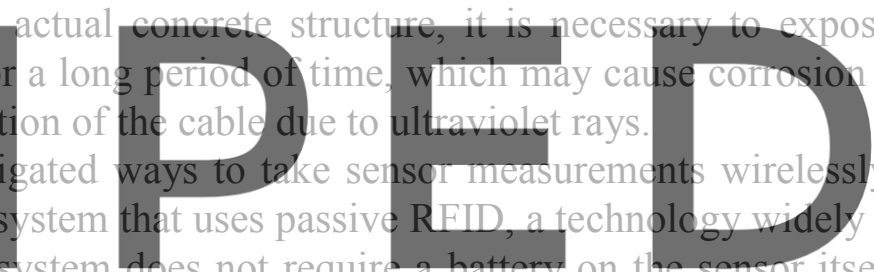

how the sensor is connected to the passive RFID.

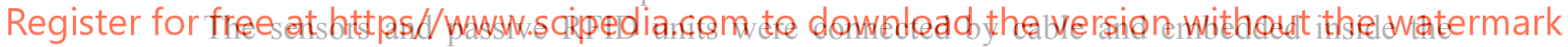

structure. To measure the electrical resistance of the sensor, an electromagnetic wave was

transmitted from the antenna of the RFID reader/writer to the RFID unit embedded in the concrete, and the measured output value was then returned to the RFID reader/writer. This system is powered by the electromotive force generated inside the RFID large-scale integration (LSI) chip.

This system enables completely non-destructive measurement with no need to expose the cables to the surface of the structure. To take a measurement, an electromagnetic wave is simply transmitted from the RFID reader/writer to the surface of the structure in which the RFID unit is embedded. The embedded sensors and RFID units do not require batteries, making them ideal for long-term maintenance without the hassle of battery replacement. 


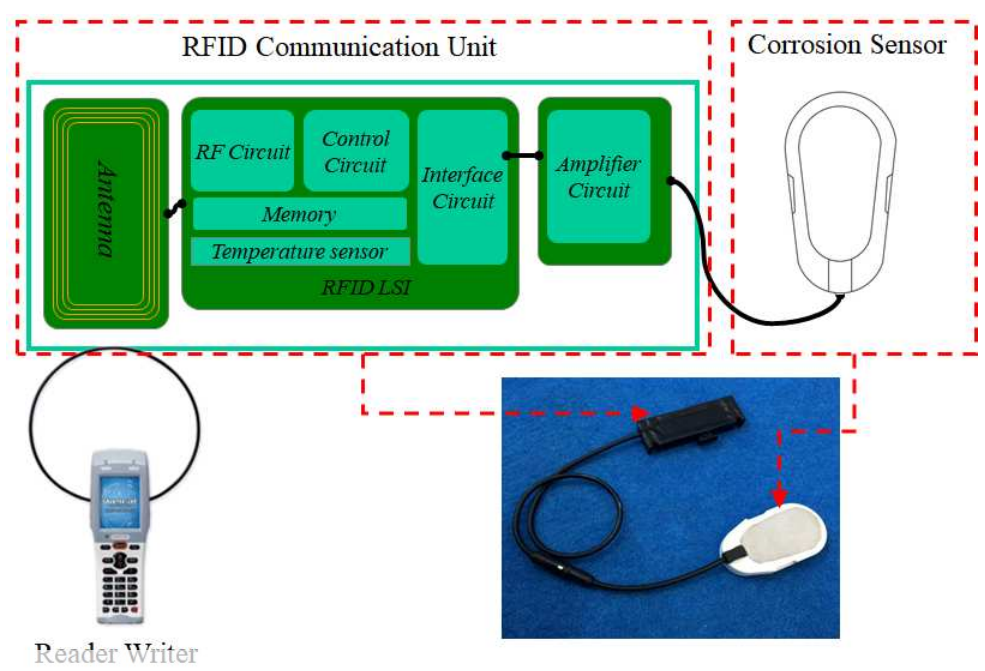

Figure 7. Configuration of the RFID corrosion sensor.

\section{Examples of Application of the Sensor and Measurement System}

The measurement system of the sensor is often used in concrete structures with high risk of steel corrosion. Major applications include port structures, such as lighthouses and piers, and road structures, including bridges where penetration of chloride ions from antifreeze agents is

a concern.

The sensor has also been usec to evaluate the repair effects show the application of the sensor to bridge pier repairs. The in 1973, in Hokkaido, Japan, and has undergone one round occurrence of rebar corrosion-induced flaking However, in j

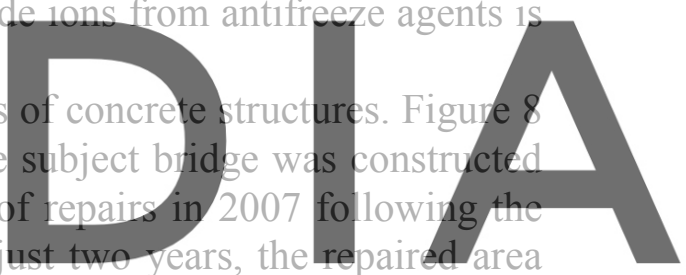
degraded. Therefore, we placed these sensors at six locations on the bridge following a second

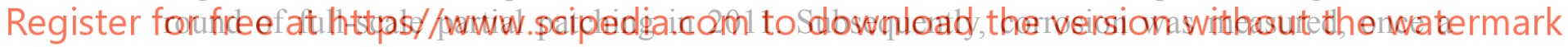
year, for five years, followed by another measurement in the seventh year. One of the sensors detected salt-induced corrosion at a location, while the other five locations were observed to be stable. We confirmed that there was no issue with the measurement performance of the sensor, and established its durability and utility as an effective maintenance management system. Corrosion at the subject structure will be measured again in 2021 and subsequent repair plans will be made based on the measurements captured by the sensors.
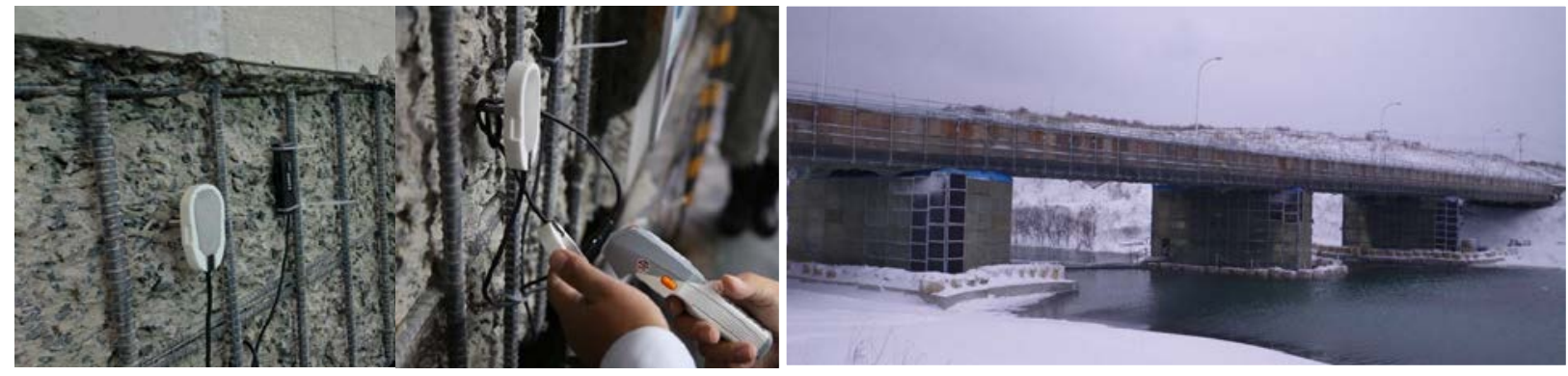

Figure 8. Application of the system to bridge pier repairs. 


\section{Conclusions}

We verified the performance of a corrosion environment sensor made of iron foil by measuring how long it took the sensor to identify corrosion under several different conditions corresponding to different chloride ion concentrations in a simulated concrete test solution. The following results were obtained:

- The corrosion environment sensor ruptured due to corrosion in environments with a chloride ion concentration of $500 \mathrm{ppm}$. The higher the chloride ion concentration, the shorter was the time to rupture.

- The fact that the sensor ruptures in an environment with a chloride ion concentration of $500 \mathrm{ppm}$, which corresponds to a corrosion rate of $0.001 \mathrm{~mm} / \mathrm{y}$, suggests that it has a highly sensitive reaction to the chloride ion concentration.

- By adopting passive RFID as the communication interface to the corrosion environment sensor, we were able to build a practical preventive maintenance system against steel corrosion.

We were able to demonstrate the long-term durability of the sensor system based on passive RFID by applying it to repair work on real structures and maintaining it for seven years with no failures.

\section{Future Work / Discussion}

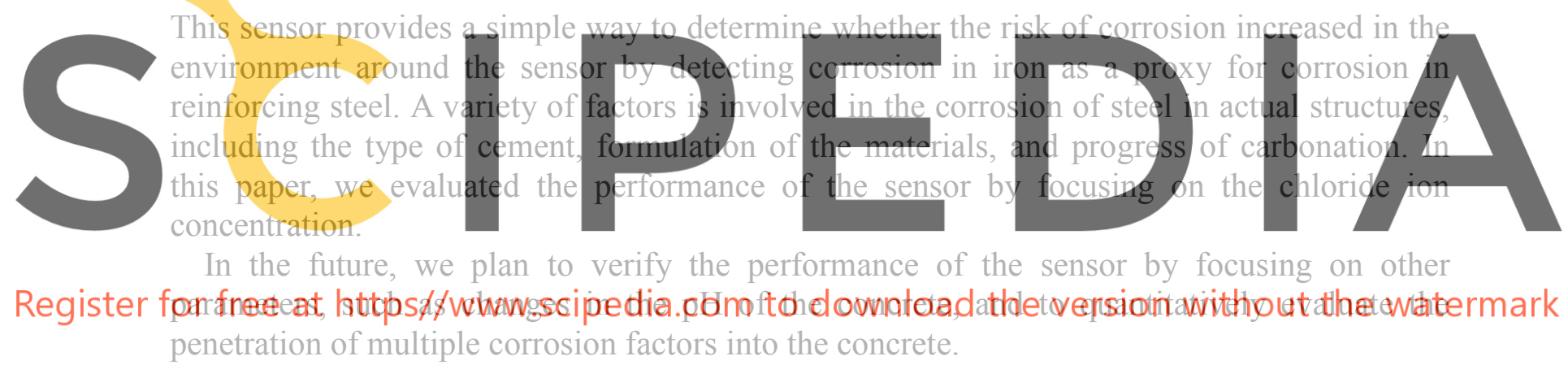

\section{ORCID}

Akira Eriguchi: https://orcid.org/0000-0001-7167-4019

\section{References}

ASTM C876-15. (2015). Standard Test Method for Corrosion Potentials of Uncoated Reinforcing Steel in Concrete.

CEB Working Party V/4.1. (Dec.1997). Strategies for Testing and Assessment of Concrete Structures Affected by Reinforcement Corrosion (draft4) BBRI-CSTC-WTCB.

Hausmann, D. A. (1967). Materials Protection, 6(11), 19-23.

Lee, H. S., Shin, S., Ahn, J., Kim, Y. and Kho, Y. (2003). Development of corrosion sensors for monitoring steel-corroding agents in reinforced concrete structures. Materials and Corrosion, 54(4), 229-234.

Takewaka, K. and Yamamoto, S. (2001). Development and research of non-destructive monitoring system for chloride penetration process in concrete. In Proceedings of the Japan Concrete Institute, 1, 1183-1188. 